\title{
The molecular impact of pigment epithelium-derived factor, PEDF, on lung cancer cells and the clinical significance
}

\author{
JINFENG CHEN ${ }^{1,2}$, LIN YE ${ }^{2}$, LIJIAN ZHANG ${ }^{1}$ and WEN G. JIANG ${ }^{2}$ \\ ${ }^{1}$ Key Laboratory of Carcinogenesis and Translational Research (Ministry of Education), Department of \\ Thoracic Surgery, Peking University School of Oncology, Beijing Cancer Hospital and Institute, \\ Beijing 100036, P.R. China; ${ }^{2}$ Metastasis and Angiogenesis Research Group, Department of Surgery, \\ Cardiff University School of Medicine, Heath Park, Cardiff, CF14 4XN, UK
}

Received November 18, 2008; Accepted December 29, 2008

DOI: 10.3892/ijo_00000324

\begin{abstract}
Pigment epithelium-derived factor (PEDF) is an endogenous protein factor that has been shown to act as antiangiognesis factor. The present study aimed to determine the direct biological effects of PEDF on lung cancer cells and deduce a clinical relevance in patients with lung cancer, major cause of death worldwide in which the knowledge of PEDF remains poor. We constructed a mammalian expression system for human PEDF produced recombinant PEDF (rhPEDF) protein from 3 T3 cells. The expression of PEDF was examined using SDS-PAGE and Western blot analysis. Using the rhPEDF protein, we investigated the biological function of PEDF in the lung cancer cells as well as endothelial cells. PEDF expression levels were assessed in a cohort of human lung cancer specimen (77 pairs of matched normal and tumour tissues), in association with patient clinical variables and survival, using quantitative analysis of PEDF. In vitro, we found that administration of rhPEDF on two lung cancer cell lines (A549 and SK-MES1) significantly reduced tumour cell growth $(\mathrm{P}<0.05)$ with no significant effect on the growth of vascular cell line (HECV). We also found that rhPEDF significantly decreased lung cancer motility and adhesion to extracellular matrix (Matrigel) when compared with the control cells $(\mathrm{P}<0.05)$. We showed that reduced PEDF levels in lung cancer tissues significantly correlated with lymph node metastasis and an overall poor prognosis in the lung cancer patients. PEDF suppresses the growth
\end{abstract}

Correspondence to: Professor Wen G. Jiang, Metastasis and Angiogenesis Research Group, Department of Surgery, Cardiff University School of Medicine, Heath Park, Cardiff, CF14 4XN, UK E-mail: jiangw@cf.ac.uk

Professor Lijian Zhang, Key Laboratory of Carcinogenesis and Translational Research (Ministry of Education), Department of Thoracic Surgery, Peking University School of Oncology, Beijing Cancer Hospital and Institute, Beijing 100036, P.R. China

E-mail: lidzhang@yeah.net

Key words: PEDF, lung cancer, cellular motility, metastasis, prognosis and motility of lung cancer cells and has a significant correlation with the clinical outcome of the patients. These results contribute to our understanding of the molecular mechanisms of PEDF and indicates a potential prognostic and therapeutic impact of PEDF in lung cancer.

\section{Introduction}

Lung cancer is one of the most prevalence cancers in the world. About $75 \%$ patients have already been found to have metastatic disease at the time when lung cancer is diagnosed. The development of metastasis is highly dependent on the process of angiogenesis. It has been shown indeed that angiogenesis and angiogenic factors are closely related to the disease progression in lung cancer. With a growing list of angiogenic factors being identified in the past decade, naturally occurring anti-angiogenic factors are rather limited in their numbers. Pigment epithelium-derived factor, PEDF is one of the few endogenous anti-angiogenic factors in the body.

PEDF was first purified from human retinal pigment epithelial cell conditioned medium with potent neuronal differentiating activity on retinoblastoma cells $(1,2)$. It is a secreted glycoprotein of $46 \mathrm{kDa}$ in size and belongs to the serine protease inhibitor superfamily (3). There are strong evidence to show that PEDF is an inhibitor of angiogenesis, the inhibitory effect of which is stronger than that of angiostatin, thrombospondin- 1 and endostatin $(4,5)$. PEDF exerts the anti-angiogenic activities by inhibiting proliferation and migration of endothelia cells and induces apoptosis in activated endothelium. PEDF may restore thrombospondin-1 (TSP-1), another angiogenesis inhibitor, and modulate vascular forming (6). PEDF can down-regulate p2(phox) and gp91(phox) expression and suppress VEGF expression. PEDF can inhibit the advanced glycation end product (AGE) signalling to vascular hyperpermeability (7). Collectively, these actions of PEDF contribute to the anti-angiogenic effect. In clinical studies, the expression pattern of PEDF has been linked to a number of pathological conditions in which angiogenesis is critical. In choroidal neovascularization (CNV) disease, an ocular angiogenesis disorder, the balance of PEDF and VEGF expressions is an important contributing factor to the disease, in that VEGF over-expression facilitates the disease 
development whereas reduced VEGF or enhanced PEDF expression can have therapeutic effects (8).

In addition to the potent effect on endothelial cells, PEDF is also known to act on other cell types. PEDF can stimulate the pericytes to synthesise platelet-derived growth factor-B (PDGF-B), a survival factor for pericytes to maintain the microvascular homeostasis (9). In neonatal astrocytes, PEDF can induce proinflammatory and immediate-early gene through the activation of nuclear factor kappa $\mathrm{B}(\mathrm{NF}-\mathrm{KB})$ or cyclin AMP-responsive element binding protein (CREB) (10). PEDF is a multi-potent factor affecting neurons and neonatal astrocytes. In neurons, expression of pro-survival genes, including c-IAP1, c-IAP2, FLIPs, A1/Bfl-1 and Mn-SOD, can be induced by PEDF. Interestingly, the pro-apoptotic Bcl-2 family members Bax and Bid were not affected by PEDF (11).

In clinical cancer, PEDF has been found to have a prognostic significance in breast cancer, liver cancer, Wilms tumour and indeed in lung cancer (12-14). These studies have shown that loss/reduced expression of PEDF facilitates disease progression and results in a poor prognosis in the patients. It has been suggested that this link to prognosis is the result of increased angiogenesis in the tumour due to the loss of anti-angiogenic control by PEDF. However, it has been recently shown that when engineered to express PEDF, certain cancer cells, such as prostate cancer, osteosarcoma, ovarian cancer, pancreatic cancer, malignant glioma, neuroblastoma, have a reduced growth rate, thus arguing for a potential direct effect of PEDF on cancer cells (15-20).

We recently reported that expression of PEDF in non-small cell lung cancer is reduced and that the reduction of PEDF is linked to a poor clinical outcome (14). We have further shown that forced expression of PEDF in endothelial cells resulted in reduction of motility and tubule formation (21). In the present study, we first produced recombinant human PEDF and then tested the direct biological effect of PEDF on lung cancer cells. Finally, we have provided first line report that expression of the PEDF transcripts was linked to the long-term survival of the patients.

\section{Materials and methods}

Cell lines, materials and human lung specimens. Human lung cancer cell line A549 (adenoma carcinoma) and SKMES1 (squamous carcinoma), fibroblast cell line NIH 3 T3 cell line and the Chinese Hamster Ovary cell line, CHO cells (American Type Culture Collection, Manassas, VA) were maintained in Dulbecco's modified Eagle's medium (DMEM) supplemented with $10 \%$ fetal calf serum (FCS) and antibiotics. HECV (ICLC HL01001) (human vascular epithelium cell) cell lines were obtained from Interlab Cell Line Collection (ICLC), Naples, Italy. The pEF6/v5-his cloning vector was purchased from Invitrogen (Pasley, Scotland, UK). Goat anti-human PEDF, mouse anti-human GAPDH antibodies and mouse anti-His antibody were obtained from Santa Cruz Biotechnology (Santa Cruz, CA). Matrigel (reconstituted basement membrane) was purchased from Collaborative Research Product (Bedford, MA, USA). Other kits and reagents were obtained from Sigma-Aldrich (Poole, UK), unless otherwise stated.
Table I. The clinical and pathological characteristics of the study cohort.

\begin{tabular}{lc}
\hline Clinical information & No. \\
\hline Sex & 52 \\
$\quad$ Male & 25 \\
Female & \\
Histologic type & 31 \\
$\quad$ Squamous & 37 \\
Adenocarcinoma & 3 \\
Small cell lung cancer & 4 \\
Other type & \\
Tumour status & 51 \\
T1-2 & 26 \\
T3-4 & \\
Lymph node status & 52 \\
N0-N1 & 25 \\
N2 & \\
TNM stage & 32 \\
I-II & 35 \\
III & \\
\hline
\end{tabular}

Fresh frozen lung tissues, 77 pairs of matched normal and tumour tissues from the same patients were obtained from patients who attended Beijing Cancer Hospital from January 2004 to August 2007, under ethics committee approval. None of the patients received any neoadjuvant therapy prior to surgery. Histological types of the lung cancers are given in Table I. Clinicopathological characteristics of the tumours were defined according to the TNM criteria of the UICC (22). These tissues were collected immediately after surgical resection at the Beijing Cancer Hospital and were stored in the Tissue Bank of Peking University Oncology School. Clinicopathological factors, including age, sex, histological types of tumours, TNM stage, and lymph node metastasis were recorded and stored in the patients' database. Patients were followed-up from the day of operation to August 2008 as the end of the follow-up for the present study. The follow-up intervals were calculated as survival intervals after surgery. For clinical data, see Table I.

Recombinant PEDF protein production with a mammalian system. We first constructed a mammalian expression system for human PEDF. The full-length PEDF gene sequence was amplified by reverse transcription-polymerase chain reaction (RT-PCR) using the primers listed in Table II. The PCR products were T-A cloned into a $\mathrm{pEF} 6 / \mathrm{v} 5$-His cloning vector (Invitrogen) which has elongation factor $\alpha$ promoter (EF6), a blasticidin resistance gene (for mammalian cells) and ampicillin resistance gene (for prokaryotic cells). The ligated product was subsequently used to transform the One-Shot E. coli 
Table II. Primer sequences.

\begin{tabular}{lll}
\hline Full length PEDF & $\begin{array}{l}\text { Forward } \\
\text { Reverse }\end{array}$ & $\begin{array}{l}\text { GACATGCAGGCCCTGGT } \\
\text { GGGGCCCCTGGGGTCCAGAA }\end{array}$ \\
PEDF & Forward & ATTCTGGGTCACTTTCAGGG \\
& Reverse & AGGTCGGAGTCAACGGATTTG \\
GAPDH & Forward & GTGATGGCATGGACTGTGGT \\
& Reverse & GGTGCTACTCCTCTGCATT \\
PEDF qPCR & Forward & ACTGAACCTGACCGTACAAGAAAGGATCCTCCTCCTC \\
\end{tabular}

(Invitrogen). Following selection of strains, which has fulllength PEDF cDNA correctly inserted, E. coli was scaled up to allow amplification of the plasmid. Plasmids were extracted, purified, and used to transfect 3T3 cell line with an Easyject Plus electroporator (EquiBio, Kent, UK). After up to 2 weeks of selection with Blasticidin $(5 \mu \mathrm{g} / \mathrm{ml})$, the transfectants were grown to sufficient number and used in the current study.

RNA preparation and analysis of gene transcript by RT-PCR. RNA was obtained using Total RNA Isolation Reagent $\left(\right.$ ABgene $\left.{ }^{\mathrm{TM}}\right)$. RNA $(0.25 \mu \mathrm{g})$ was used to produce the first strand cDNA using a Reverse transcription kit (Sigma, Poole, Dorset, UK). PCR was undertaken using a REDTaq ${ }^{\mathrm{TM}}$ ReadyMix PCR reaction mix (Sigma-Aldrich, Inc.). Cycling conditions for the reaction were $94^{\circ} \mathrm{C}$ for $5 \mathrm{~min}$, followed by 40 cycles of $94^{\circ} \mathrm{C}$ for $30 \mathrm{sec}, 58^{\circ} \mathrm{C}$ for $30 \mathrm{sec}$, and $72^{\circ} \mathrm{C}$ for $40 \mathrm{sec}$. This was followed by a final extension of $10 \mathrm{~min}$ at $72^{\circ} \mathrm{C}$. The quality of cDNA was verified by 532-bp GAPDH PCR product with the anneal temperature of $55^{\circ} \mathrm{C}$ (primers for PEDF and GAPDH were listed in Table II). Products were separated by $2 \%$ agarose gel and stained with ethidium bromide, visualizing under UV light.

SDS-PAGE and Western blotting to test the expression situation of PEDF plasmid. Cells were pelleted and protein extracted in HCMF buffer $\left(160 \mathrm{mM} \mathrm{NaCl}, 0.6 \mathrm{mM} \mathrm{Na}_{2} \mathrm{HPO}_{4}\right.$, $0.1 \% \mathrm{w} / \mathrm{v}$ glucose and $0.01 \mathrm{M}$ HEPES, $\mathrm{pH}$ 7.4) containing $0.5 \%$ Triton $\mathrm{X}-100,2 \mathrm{mM} \mathrm{CaCl}, 100 \mu \mathrm{g} / \mathrm{ml}$ phenylmethylsulfonyl fluoride, $1 \mu \mathrm{g} / \mathrm{ml}$ leupeptin, and $1 \mu \mathrm{g} / \mathrm{ml}$ aprotinin for $30 \mathrm{~min}$. They were clarified at $13,000 \mathrm{x} \mathrm{g}$ for $15 \mathrm{~min}$. Protein concentrations were measured using fluorescamine and quantified by using a multifluoroscanner (Denly, Sussex, UK). Equal amounts of protein from each cell sample were denatured in a sample buffer and boiled for $5 \mathrm{~min}$, before separated on a $10 \%$ (for PEDF and GAPDH) polyacrylamide gel. Following electrophoresis, proteins were blotted onto nitrocellulose sheets and blocked in $10 \%$ skimmed milk (w/v in TBS) for $1 \mathrm{~h}$ before probing with the appropriate antibody. The membrane was probed with peroxidase-conjugated secondary antibody (1:1000). Protein bands were visualised with the ECL system (Amersham, UK). The band densities on the photographic film were analyzed with a UVI tech imager (UVI TECH, Cambridge, UK) and are shown as relative values.

Preparation of recombinant human rhPEDF protein from the condition medium of $3 T 3$ cell transfected with PEDF expression construct. Conditioned media from $3 \mathrm{~T} 3$ cells, transfected with the PEDF expression vector, and containing rhPEDF were collected from roller bottles. PEDF proteins were purified from the conditioned media by Ni-NTA heavy metal Affinity columns (Amersham Biosciences AB, Sweden) according to the manufacturer's instructions. A binding buffer (8X PBS $3 \mathrm{ml} ; 2 \mathrm{mmol} / 1$ Imidazole $0.12 \mathrm{ml}$; $\mathrm{H}_{2} \mathrm{O}$ to $24 \mathrm{ml}$; $\mathrm{pH}$ 7.4-7.6) and an elution buffer (8X PBS $3 \mathrm{ml}$; Iimidazole $(2,1,0.5,0.25$ and $0.125 \mathrm{mmol} / \mathrm{l}) 2 \mathrm{ml} ; \mathrm{H}_{2} \mathrm{O}$ to $8 \mathrm{ml}$; pH 7.4-7.6) were used for preparing the column and for elution of recombinant proteins. The final concentration of Imidazole in the elution buffer was 500, 250, 125, 62.5 and $31.3 \mathrm{mM}$. After initial washing, the columns were charged with $0.5 \mathrm{ml}$ of $0.1 \mathrm{M} \mathrm{NiSO}_{4}$. This was followed by adding binding buffer, loading samples, washing the columns and eluting rhPEDF with elution buffer. The presence and the purity of rhPEDF were verified using Western blotting with anti-His and anti-PEDF antibodies. Protein concentration was calculated using a BioRad DC protein assay kit (Bio-Rad Laboratories, Hercules, CA).

In vitro cell growth assay. This was based on a previously reported method (23). Cells were plated into a 96-well plate at 2,000 cells/well after a period of incubation. SkMes1, A549 lung cancer cells and HECV cells were treated with or without various concentration of rhPEDF. Cells were fixed in $10 \%$ formaldehyde on the day of plating and daily for the subsequent days, $0.5 \%$ crystal violet $(\mathrm{w} / \mathrm{v})$ was used to stain the cells. Following washing, the stained crystal violet was dissolved with $10 \%(\mathrm{v} / \mathrm{v})$ acetic acid and the absorbance was determined at a wavelength of $540 \mathrm{~nm}$ using an ELx800 spectrophotometer. Absorbance represents the cell number.

Cell-matrix adhesion assay. This was based on a method we previously reported (24). The 96-well plate was coated with $5 \mu \mathrm{g}$ of Matrigel and allowed to dry. Following rehydration, 40,000 cells were added to each well. After $40 \mathrm{~min}$ of incubation non-adherent cells were washed off using BSS buffer. 


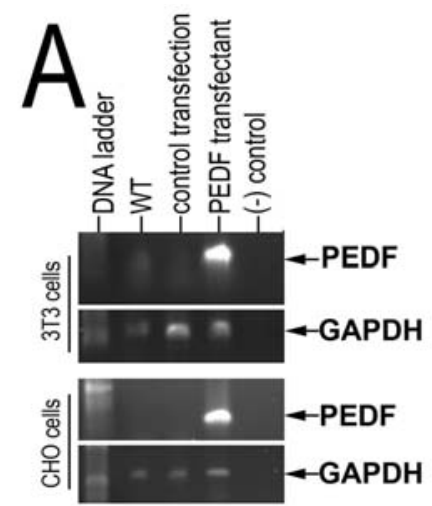

B

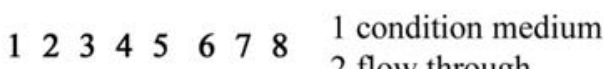

2 flow through

anti-PEDF_ 3 Wash through

4 Elution in $31.3 \mathrm{mM}$

5 Elution in $62.5 \mathrm{mM}$

anti-His- $\quad \begin{aligned} & \text { 6 Elution in } 125 \mathrm{mM} \\ & 7 \text { Elution in } 250 \mathrm{mM}\end{aligned}$

8 Elution in $500 \mathrm{mM}$

Figure 1. Establishment of 3T3 cells and CHO cells for expressing PEDF (A) and purification of rhPEDF using metal chelating chromatography (B). A, 3T3 cells and $\mathrm{CHO}$ cells successfully expressed human PEDF transcripts after transfection. B, Purified rhPEDF protein from condition medium of 3T3 cells. Shown are the test conditions for eluting the recombinant protein from the Nickel chelating chromatography column. Using the elution buffer with $125 \mathrm{mM}$ imidazole, we obtained purified rhPEDF protein from the condition medium testing with the anti-PEDF and anti-His antibody.

The remaining cells were fixed with $4 \%$ formalin and stained with $0.5 \%$ crystal violet. The number of adherent cells was then counted under microscopy.

In vitro motility assay using cytodex-2 beads. We followed the protocol described by Rosen et al (25). Cells $\left(1 \times 10^{6}\right)$ were incubated with $100 \mu \mathrm{l}$ Cytodex-2 beads (Pharmacia, Piscataway, NJ) in $10 \mathrm{ml}$ DMEM medium overnight to allow cells to adhere to the cytodex-2 beads. After the medium was aspirated and the beads were washed with DMEM, they were aliquated into wells of a 24 -well plate $(100 \mu \mathrm{l} /$ well $)$. After $4 \mathrm{~h}$ of incubation, the beads were washed off. The cells that migrated onto the bottom of each well were fixed with $4 \%$ formalin for $5 \mathrm{~min}$ and were stained with $0.5 \%$ crystal violet. The cells were counted under a microscope. The experiment was performed three times.

PEDF expression level in lung cancer and normal lung tissue assessed by real-time RT-PCR. Level of PEDF transcript from the above prepared cDNA was determined using real-time quantitative PCR based on the Amplifluor ${ }^{\mathrm{TM}}$ technology, modified from a method reported previously (26). PCR primers were designed using Beacon Design software (Biosoft International, Palo Alto, CA, USA), but to the reverse primer an additional sequence, known as the $\mathrm{Z}$ sequence (5'-actg aacctgaccgtaca-3') which is complementary to the universal $\mathrm{Z}$ probe (Intergen Inc., Oxford, UK) was added. Primers for PEDF quantitation are listed in Table II. The reaction was carried out using the following condition: Hot-start Q-master mix (Abgene), 10 pmol of specific forward primer, 1 pmol reverse primer which has the $Z$ sequence, 10 pmol of FAM tagged probe (Intergen Inc. Oxford, UK) and cDNA. The reaction was carried out using the IcyclerIQ (Bio-Rad, Hemel Hemstead, UK) which is equipped with an optic unit that allows real-time detection of 96 reactions under the following conditions: $94^{\circ} \mathrm{C}$ for $12 \mathrm{~min}$ and 65 cycles of $94^{\circ} \mathrm{C}$ for $15 \mathrm{sec}$, $55^{\circ} \mathrm{C}$ for $60 \mathrm{sec}$ and $72^{\circ} \mathrm{C}$ for $20 \mathrm{sec}$. The level of PEDF transcript was generated from a standard that was simultaneously amplified with the samples. Expression level of PEDF gene was then normalized against actin expression already measured in these specimens, to correct for varying amounts of epithelial tissue between samples (26).
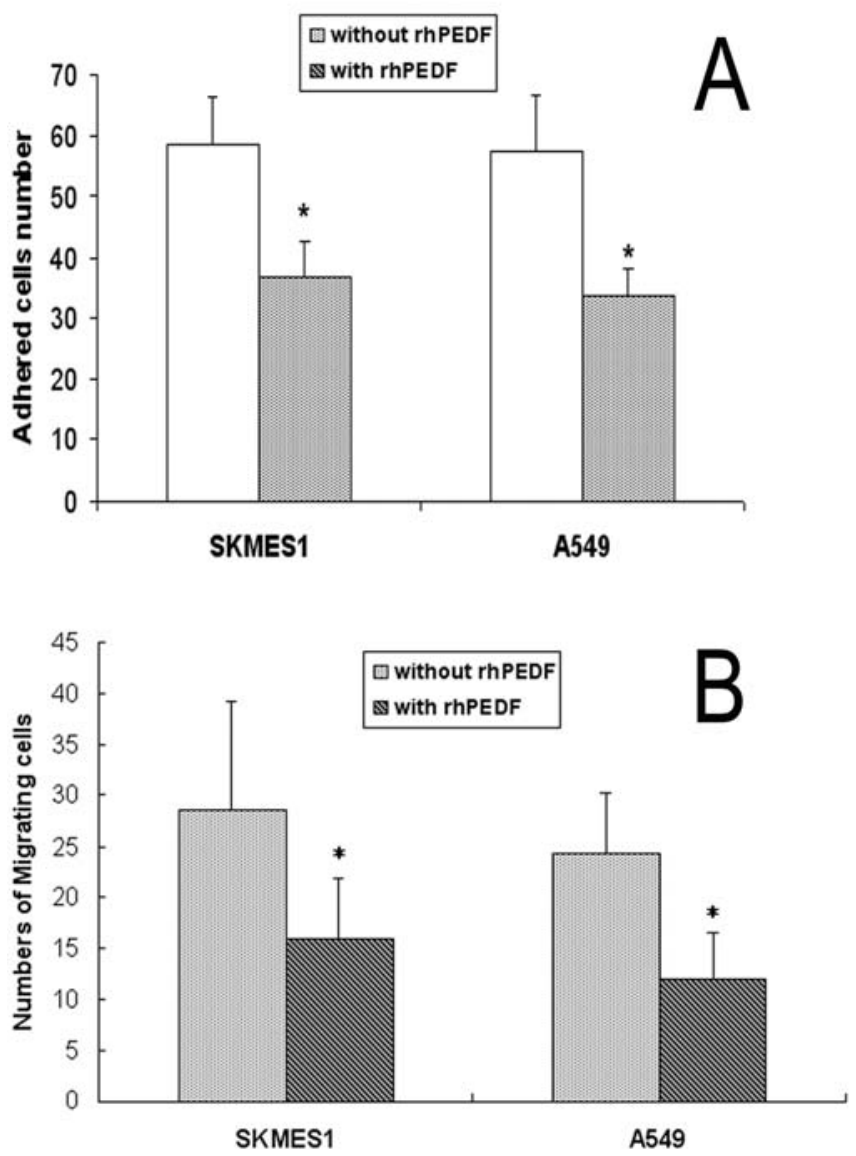

Figure 2. Effect of PEDF on cell biological behaviour of SKMES1 and A549 cells. A, PEDF significantly suppressed SKMES1 and A549 lung cancer cell-matrix adhesion compared to the control cells. B, PEDF significantly suppressed SKMES1 and A549 lung cancer cell invasion $(\mathrm{P}<0.05)$ compared to the control cells. Asterisk indicates $\mathrm{P}<0.05$.

Statistical analysis. Minitab ${ }^{\circledR}$, version 14 was used for analysis. Non-normally distributed data were assessed using the Mann-Whitney U test, and the 2 sample t-test was used for normally distributed data. Differences were considered statistically significant at $\mathrm{P}<0.05$. Survival curve was constructed using the Kaplan-Meier method (SPSS version 12.0.0). 
A

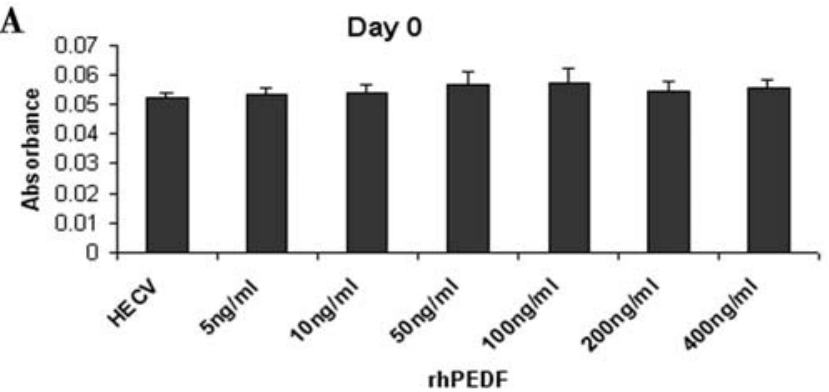

B

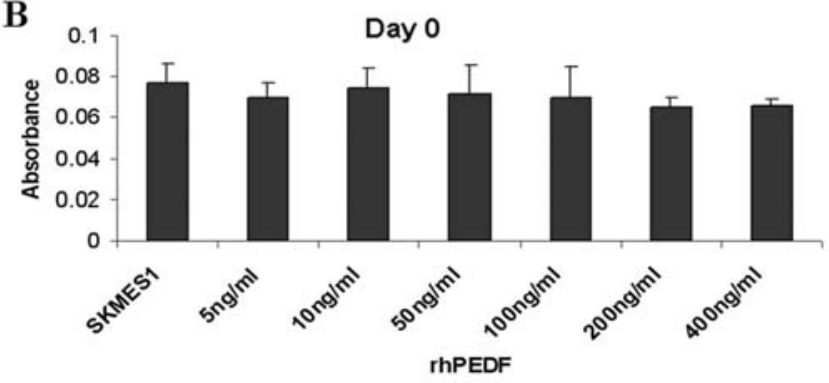

C

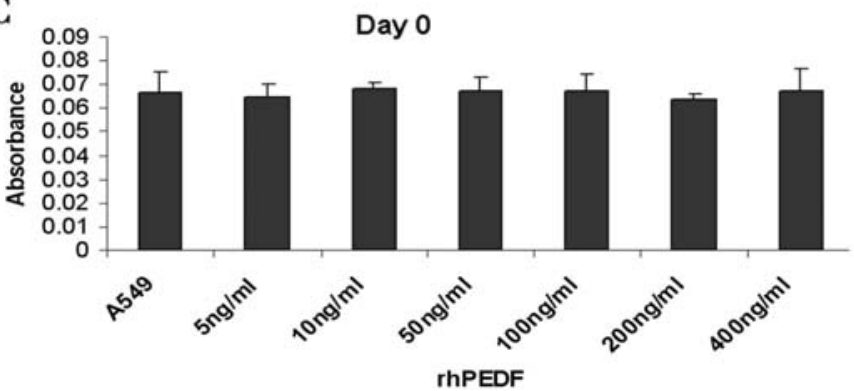

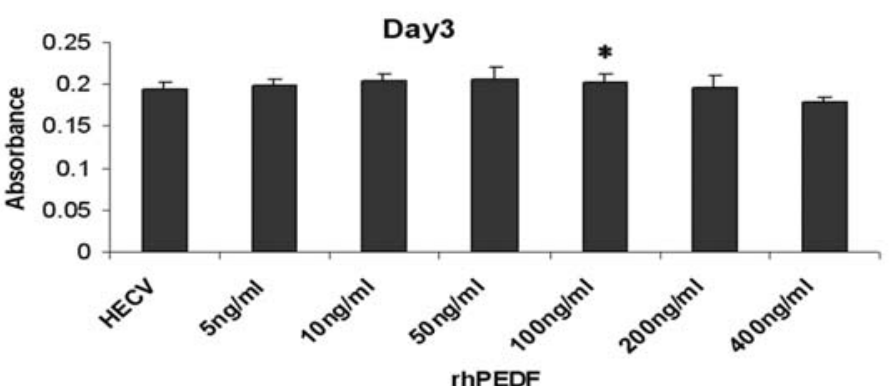

rhPEDF

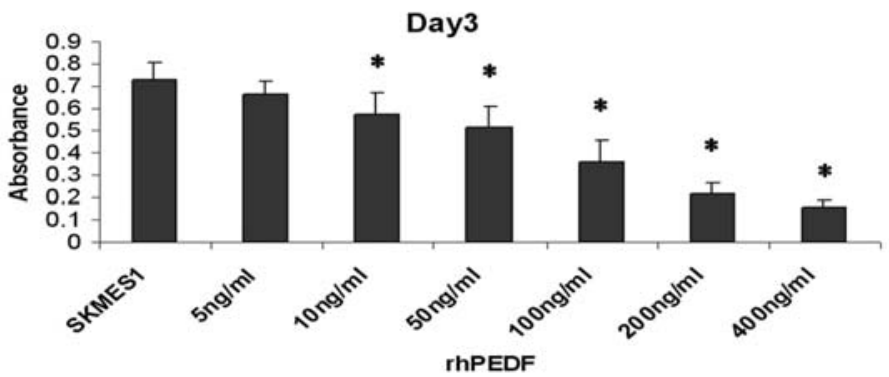

Day3

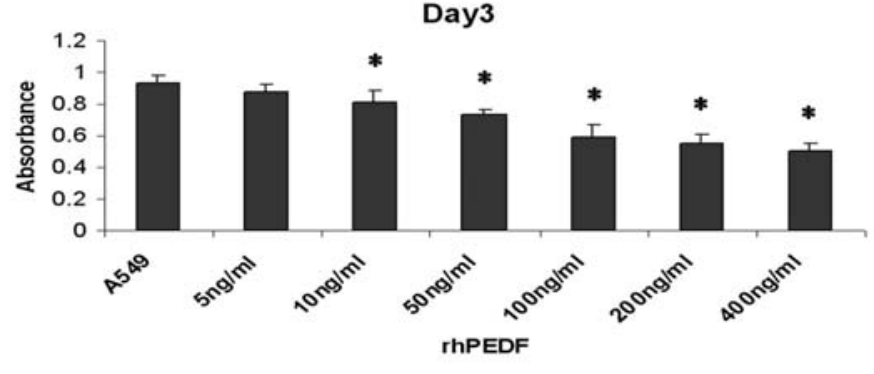

Figure 3. Effect of different concentrations of PEDF on the growth of HECV and lung cancer cells in vitro. A, HECV cells; B, SKMES1 cells; C, A549 lung cancer cells. Left panel, 0 days; right panel, 3 days. Exogenous PEDF protein significantly reduced the growth of both lung cancer cells at concentrations $>10 \mathrm{ng} / \mathrm{ml}$. However, rhPEDF only affected the growth of HECV cells at a higher concentration.

\section{Results}

Over-expression of PEDF and preparation of rhPEDF. Both $3 \mathrm{~T} 3$ cells and $\mathrm{CHO}$ cells were transfected with PEDF expression construct and successfully expressed PEDF transcript as shown by RT-PCR (Fig. 1A). Direct DNA sequencing of the PCR product confirmed that the transcript from the transfected cells was PEDF. Subsequent analysis has shown that $3 \mathrm{~T} 3$ secreted rhPEDF more efficiently than $\mathrm{CHO}$ cells. 3T3 cells were therefore chosen as the source of recombinant PEDF. Western blot analysis showed 3T3 cell transfect with the PEDF plasmid could over-express PEDF protein (Fig. 1). rhPEDF thus generated displayed a single band with a molecular weight of $\sim 46 \mathrm{kDa}$. As showed in Fig. 1B, $125 \mathrm{mM}$ Imidazole in the elution buffer was the optimal condition and was used in the present study. Sodium dodecyl sulphatepolyacrylamide gel electrophoresis analysis of purified PEDF proteins, with anti-PEDF and anti-His antibody, revealed a single band with a molecular weight of $\sim 46 \mathrm{kDa}$, which showed reactivity with the human PEDF antibody (Fig. 1B).

Effect of rhPEDF on lung cancer cell adhesion and motility in vitro. When treated with rhPEDF, lung cancer cell lines, SKMES1 and A549, displayed significant changes in cellular motility and cell-matrix adhesion compared with the cancer cells without rhPEDF protein. rhPEDF inhibited lung cancer cell matrix adhesion, using the in vitro cell matrix adhesion technique. The number of adherent cells for the SKMES1 cells treated with rhPEDF were 36.78 \pm 5.93 compared with the cells not treated with rhPEDF $(58.56 \pm 7.90)$ $(\mathrm{P}<0.05$, Fig. 3A). The number of adherent cells for the A549 cells treated with rhPEDF were $33.78 \pm 4.29$ compared with the cells not treated with rhPEDF $(57.56 \pm 9.10)(\mathrm{P}<0.05$, Fig. 2A).

rhPEDF also significantly reduced the motility of SKMES1 and A549 cells. The number of migrating SKMES1 cells treated with rhPEDF was $15.8 \pm 6.09$ compared with $28.6 \pm 10.66$ for SKMES1 without rhPEDF (Fig. 3B). The number of migrating A549 cells treated with rhPEDF was $12 \pm 4.49$ compared with 24.4 \pm 5.78 for A549 without rhPEDF (Fig. 2B).

PEDF inhibited the growth of lung cancer cells in vitro, with little impact on the growth of vascular cells. We firstly evaluated the anti-proliferative effect of rhPEDF treatment on human vascular cell line (HECV) and two lung cancer cell lines, SKMES1 and A549 cell lines. All cell lines were treated with increasing concentration of $\operatorname{rhPEDF}(5,10,50,100,200$ and $400 \mathrm{ng} / \mathrm{ml}$ ) over a 4-day period, with culture medium as a control. On HECV cells, rhPEDF had no significant effect on the growth except that at a concentration of $100 \mathrm{ng} / \mathrm{ml}$, 

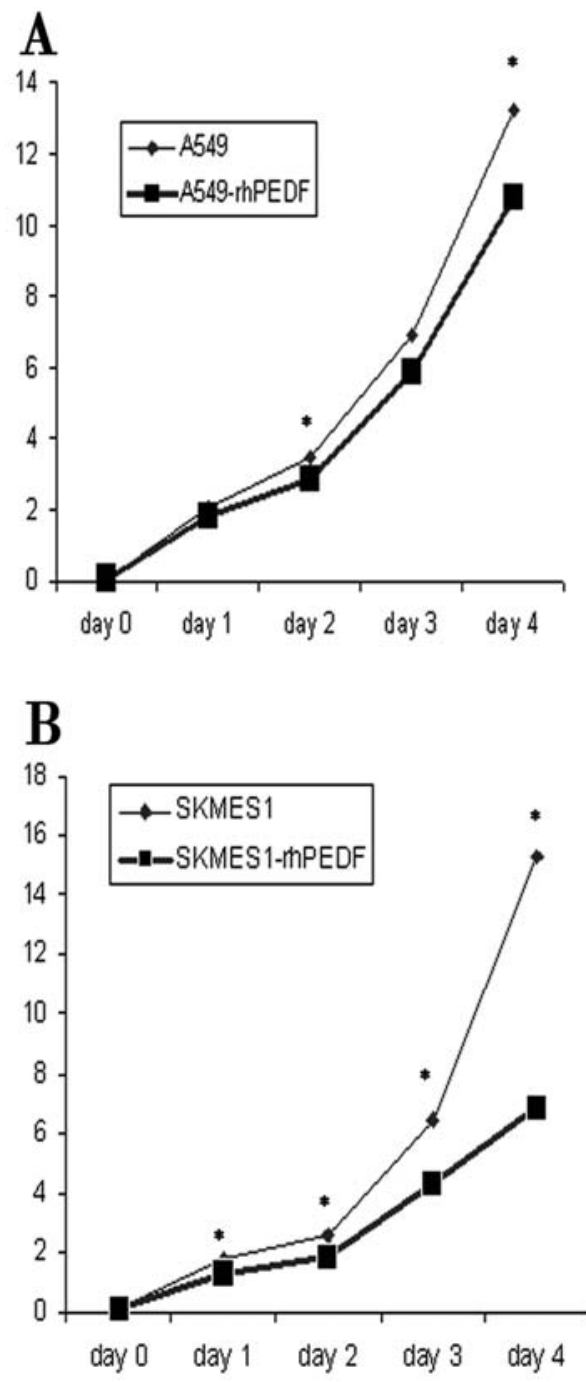

Figure 4. Time course of rhPEDF induced growth inhibition of SKMES1 and A549 were inhibited with rhPEDF protein. Shown are the percentage reduction of the growth of the cells. rhPEDF significantly inhibited the growth after 2-day treatment.

rhPEDF reduced the growth $(\mathrm{P}=0.041)$ (Fig. 3A). However, in both SKMES1 and A549 cells, a statistically significant dose-dependent reduction in cell proliferation was observed (Fig 3B and C). In SKMES1 cells, after 3-day treatment with rhPEDF resulted in an $8.39 \%(5 \mathrm{ng} / \mathrm{ml})(\mathrm{P}=0.144), 21.35 \%$ $(10 \mathrm{ng} / \mathrm{ml})(\mathrm{P}=0.006), 29.32 \%(50 \mathrm{ng} / \mathrm{ml})(\mathrm{P}=0.027), 51.7 \%$ $(100 \mathrm{ng} / \mathrm{ml})(\mathrm{P}<0.001), 70.81 \%(200 \mathrm{ng} / \mathrm{ml})(\mathrm{P}<0.001)$, $78.68 \%(400 \mathrm{ng} / \mathrm{ml})(\mathrm{P}<0.001)$ reduction in cell numbers compared to control (Fig. 3B). In A549 cells, a similar effect on cell proliferation was also seen with rhPEDF (Fig. 3C). In A549 cells, after 3-day treatment with rhPEDF resulted in a $6.6 \%(5 \mathrm{ng} / \mathrm{ml})(\mathrm{P}=0.05), 12.96 \%(10 \mathrm{ng} / \mathrm{ml})(\mathrm{P}=0.014)$, $21.44 \%(50 \mathrm{ng} / \mathrm{ml})(\mathrm{P}<0.001), 37.14 \%(100 \mathrm{ng} / \mathrm{ml})(\mathrm{P}=0.001)$, $40.48 \%$ (200 ng/ml) $(\mathrm{P}<0.001), 45.75 \%$ (400 ng/ml) $(\mathrm{P}<0.001)$ reduction in cell numbers compared to control. As shown in Fig. 4A, A549 cells treated with rhPEDF showed a significant decrease in growth rate compared with A549 control cells on the second day $(\mathrm{P}=0.007)$ and the fourth day $(\mathrm{P}=0.014)$. SKEMS1 cells treated with rhPEDF also showed a significant decrease in growth compared with the wild-type
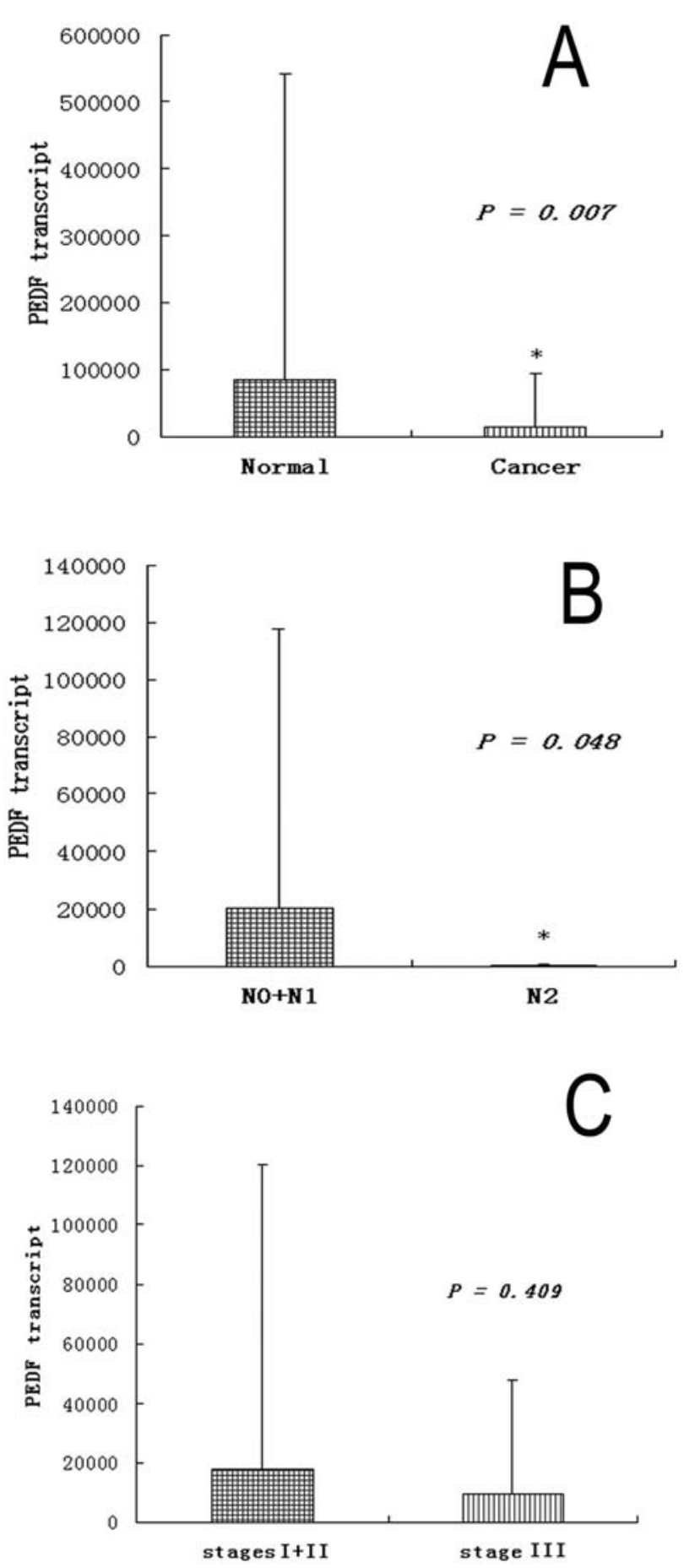

Figure 5. Quantitative PCR analysis of PEDF expression in human lung cancer tissue. A, The level of PEDF expression from patients in cancer tissue was significantly lower than the PEDF level in normal tissue $(\mathrm{P}=0.007)$. $\mathrm{B}$, Patients with lymph node distant metastasis (N2) have significantly reduced levels of PEDF expressed in their tumours compared with the tumours of patients with no lymph node distant metastasis $(\mathrm{N} 0+\mathrm{N} 1)(\mathrm{P}=0.048)$. C, Patients with local advanced stage (stage III) have reduced levels of PEDF expressed in their tumours compared with the tumours of patients with early stage (stages $\mathrm{I}+\mathrm{II})$, but it is not significant $(\mathrm{P}=0.409)$.

control cells on the first day $(\mathrm{P}=0.001)$, second day $(\mathrm{P}=0.005)$, third day $(\mathrm{P}=0.011)$ and the fourth day $(\mathrm{P}<0.001)(\mathrm{Fig} .4 \mathrm{~B})$.

The clinical analysis of PEDF gene expression in lung cancer. We quantified the PEDF transcripts in lung cancer specimens 


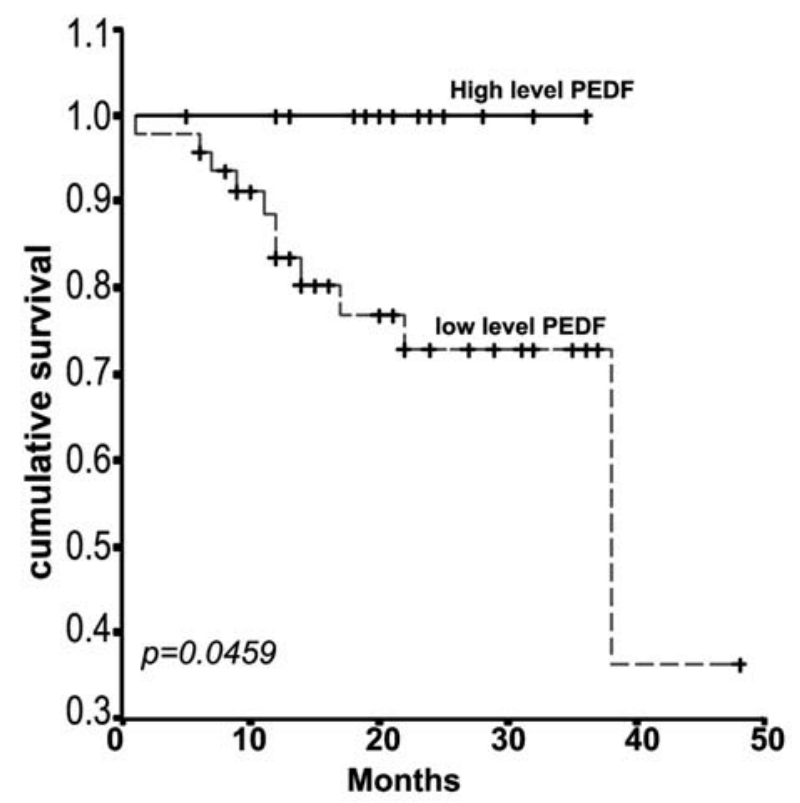

Figure 6. Kaplan-Meier analysis of overall survival of lung cancer patients depending on the expression level of PEDF mRNA. High level of PEDF was associated with significantly longer survival compared with those who had low level $(\mathrm{P}=0.0459)$.

(tumour, $n=77$; matched paired tissue, $n=77$ ) using real-time quantitative PCR (all values are displayed as mean PEDF transcript copies $/ \mu 1$ ). We report that normal lung tissues had significantly higher levels of PEDF transcript than tumour tissues $(84875.6 \pm 455956.47$ copies $/ \mu 1$ for normal tissues vs. $14029.43 \pm 79922.47$ for tumour tissues, $\mathrm{P}=0.007$, Fig. 5A). PEDF expression levels were assessed in relation to lymph node metastasis status $(\mathrm{N} 0+\mathrm{N} 1, \mathrm{n}=52 ; \mathrm{N} 2, \mathrm{n}=25)$ and tumour TNM stage (I+II stage, $\mathrm{n}=42$; III stage, $\mathrm{n}=35$ ). The tumours with distant lymph node metastasis (N2) $(248.96 \pm 181.58$ copies/ $\mu$ l) had significantly reduced levels of PEDF compared with tumours with no distant lymph node metastasis $(\mathrm{N} 0+\mathrm{N} 1)$ $(20654.66 \pm 13431.13$ copies $/ \mu 1)(\mathrm{P}=0.048)$ (Fig. 5B). We also analyzed PEDF expression in relation with the TNM staging of the tumours. We showed that PEDF levels were reduced in patients with stage III $(9722.854 \pm 6511.963$ copies/ $\mu 1)$ compared with the early stage (I+II stage) patients (17618.24 \pm 15871.96 copies $/ \mu 1$ ) (Fig. 5C). Although it was not statistically significant $(\mathrm{P}=0.409)$. After 48 months of follow-up, patients were analyzed for survival time based on PEDF expression level. The mean time of follow-up for the cohort ( $\mathrm{n}=77)$ was 19.46 months (range $1-48$ months). The mean (SD) survival time was $19.46 \pm 10.18$ months. Cumulative survival curves were calculated using the KaplanMeier method. In the patients with high level expression of PEDF there was almost no deaths during the follow-up time of 36 months. In the patients with low expression level of PEDF the mean survival time was 34.63 months (95\%CI: 27.87-41.40). The levels of PEDF mRNA expression were negatively correlated with cumulative survival time. Patients with high level of PEDF had significantly longer survival time than the patients with low level of PEDF $(\mathrm{P}=0.0459$, Fig. 6)

\section{Discussion}

PEDF is one of the most potent anti-angiogenic factors, and is a pleiotropic factor initially identified as a neurotrophin (2). The factor has been shown to have a strong anti-angiogenic effect, in vitro and, in clinical studies, has an aberrant pattern of expression. In the present study, we have provided evidence that PEDF has a direct effect on lung cancer cells.

It has been reported that PEDF can dramatically suppress primary osteosarcoma and prevent development of macroscopic pulmonary metastases in vivo (19). Loss of PEDF expression was found in human prostate tumours and associated with the progression toward a metastatic phenotype, and microarray analysis showed over-expression of PEDF in prostate cancer cell associated with cell functional activites, such as protein binding, signal transduction activity and cell invasion (20). Our previous study showed that PEDF was also expressed in lung cancer tissue (14). The present study first sought to demonstrate the direct biological function of PEDF in lung cancer and has shown that exogenous rhPEDF had a marked inhibitory effect on cellular motility and adhesion of human lung cancer cells. It is interesting to note that the inhibitory effects of rhPEDF on lung cancer cells was more effective and sensitive than that seen on endothelial cells. In view of our data, we suggest that PEDF has an important role in controlling the invasiveness and migration of lung cancer cells.

Although PEDF has been shown to inhibit tumour-induced angiogenesis (27), our present study shows that rhPEDF exerts an inhibitory effect on the growth of vascular cells only at much higher concentrations $(>100 \mathrm{ng} / \mathrm{ml})$. Collectively, it suggests that PEDF influences angiogenesis through affecting the angiogenesis process without significantly affecting the proliferation of vascular endothelial cells.

The impact of PEDF in cancer has been reported in recent years. PEDF has been shown to have a potential function to inhibit cancer, including osteosarcoma, ovarian carcinoma and prostate cancer (18-20). Our previous study showed that high levels of PEDF expression in lung cancer tissue were correlated with patients prognosis and that PEDF was an important factor in lung cancer development (14). However, there has been no studies whether PEDF protein has a direct influence on the growth of lung cancer cells. With two human lung cancer cell lines, our tests showed PEDF can significantly inhibit cell growth (Figs. 3B and C and 4). Collectively, PEDF has a direct effect on the biological behaviour of lung cancer cells. Together with its potential anti-angiogenic effect, PEDF does indeed have a potential value in cancer treatment.

The potential clinical value of PEDF in lung cancer is further reflected in our clinical studies, in which we used real-time PCR to measure PEDF expression level in lung tissue and analysed the correlation with the clinicopathological data. The present study is the first to use a large cohort of lung tissue samples to determine the range and level of PEDF in lung cancer and report that in human lung cancer, transcript levels of PEDF are lower than that in normal tissues (Fig. 5A). Loss of PEDF expression may have a role in the process of lung cancer development. PEDF gene expression level has a relationship with the lymph node metastasis in lung cancer patients (Fig. 5B). Moreover, high levels of 
PEDF were not significantly correlated with TNM stage (Fig. 5C). Our previous study using SYFRE GREEN method to test PEDF expression level in 21 NSCLC samples showed that PEDF level was significantly lower than the normal tissue (14). Low levels of PEDF have been previously reported in breast cancer and glioma $(28,29)$. Taken together, we can conclude that PEDF may be a protective factor for patients with lung cancer and it has an important role to play in lymph node metastasis from lung cancer.

In conclusion, PEDF is a potent lung cancer suppressor and is associated with the long-term survival of the patients. PEDF has multifunctional activity in inhibiting lung cancer growth and preventing tumour cell motility, making it a potential candidate for targeted anticancer therapeutics.

\section{Acknowledgements}

Cancer Research Wales and Cancer Research, UK, the Beijing Municipal Science \& Technology commission and the Albert Hung Foundation (HK) are acknowledged for their support. The authors wish to thank Dr Yue Yang for his help in the clinical aspect of the study.

\section{References}

1. Tombran-Tink $\mathbf{J}$ and Johnson LV: Neuronal differentiation of retinoblastoma cells induced by medium conditioned by human RPE cells. Invest Ophthalmol Vis Sci 30: 1700-1707, 1989.

2. Tombran-Tink J, Chader GG and Johnson LV: PEDF: a pigment epithelium-derived factor with potent neuronal differentiative activity. Exp Eye Res 53: 411-414, 1991

3. Steele FR, Chader GG, Johnson LV and Tombran-Tink J: Pigment epithelium-derived factor: neurotrophic activity and identification as a member of the serine protease inhibitor gene family. Proc Natl Acad Sci USA 90: 1526-1530, 1993.

4. Dawson DW, Volpert OV, Gillis P, Crawford SE, Xu H, Benedict W and Bouck NP: Pigment epithelium-derived factor: a potent inhibitor of angiogenesis. Science 285: 245-248, 1999

5. Duh EJ, Yang HS, Suzuma I, Miyagi M, Youngman E, Mori K, Katai M, Yan L, Suzuma K, West K, Davarya S, Tong P, Gehlbach P, Pearlman J, Crabb JW, Aiello LP, Campochiaro PA and Zack DJ: Pigment epithelium-derived factor suppresses ischemia-induced retinal neovascularization and VEGF-induced migration and growth. Invest Ophthalmol Vis Sci 43: 821-829, 2002.

6. Aparicio S, Sawant S, Lara N, Barnstable CJ and Tombran-Tink J: Expression of angiogenesis factors in human umbilical vein endothelial cells and their regulation by PEDF. Biochem Biophys Res Commun 326: 387-394, 2005.

7. Yamagishi S, Nakamura K, Matsui T, Inagaki Y, Takenaka K, Jinnouchi Y, Yoshida Y, Matsuura T, Narama I, Motomiya Y, Takeuchi M, Inoue H, Yoshimura A, Bucala R and Imaizumi T: Pigment epithelium-derived factor inhibits advanced glycation end product-induced retinal vascular hyperpermeability by blocking reactive oxygen species-mediated vascular endothelial growth factor expression. J Biol Chem 281: 20213-20220, 2006

8. Tong JP and Yao YF: Contribution of VEGF and PEDF to choroidal angiogenesis: a need for balanced expressions. Clin Biochem 39: 267-276, 2006.

9. Yamagishi S, Nakamura K, Takenaka K, Matsui T, Jinnouchi Y and Imaizumi T: Pigment epithelium-derived factor (PEDF) promotes growth of pericytes through autocrine production of platelet-derived growth factor-B. Microvasc Res 69: 128-1234, 2005.

10. Yabe T, Kanemitsu K, Sanagi T, Schwartz JP and Yamada H: Pigment epithelium-derived factor induces pro-survival genes through cyclic AMP-responsive element binding protein and nuclear factor kappa B activation in rat cultured cerebellar granule cells: Implication for its neuroprotective effect. Neuroscience 133: 691-700, 2005
11. Yabe T, Sanagi T, Schwartz JP and Yamada H: Pigment epithelium-derived factor induces pro-inflammatory genes in neonatal astrocytes through activation of NF-kappa B and CREB. Glia 50: 223-234, 2005.

12. Uehara H, Miyamoto M, Kato K, Ebihara Y, Kaneko H, Hashimoto H, Murakami Y, Hase R, Takahashi R, Mega S, Shichinohe T, Kawarada Y, Itoh T, Okushiba S, Kondo S and Katoh $\mathrm{H}$ : Expression of pigment epithelium-derived factor decreases liver metastasis and correlates with favorable prognosis for patients with ductal pancreatic adenocarcinoma. Cancer Res 64: 3533-3537, 2004.

13. Abramson LP, Browne M, Stellmach V, Doll J, Cornwell M, Reynolds M, Arensman RM and Crawford SE: Pigment epithelium-derived factor targets endothelial and epithelial cells in Wilms' tumour. J Pediatr Surg 41: 1351-1356, 2006.

14. Zhang L, Chen J, Ke Y, Mansel RE and Jiang WG: Expression of pigment epithelial derived factor is reduced in non-small cell lung cancer and is linked to clinical outcome. Int J Mol Med 17: 937-944, 2006.

15. Guan M, Pang CP, Yam HF, Cheung KF, Liu WW and Lu Y: Inhibition of glioma invasion by overexpression of pigment epithelium-derived factor. Cancer Gene Ther 11: 325-332, 2004.

16. Hase R, Miyamoto M, Uehara H, Kadoya M, Ebihara Y, Murakami Y, Takahashi R, Mega S, Li L, Shichinohe T, Kawarada Y and Kondo S: Pigment epithelium-derived factor gene therapy inhibits human pancreatic cancer in mice. Clin Cancer Res 11: 8737-8344, 2005.

17. Streck CJ, Zhang Y, Zhou J, Ng C, Nathwani AC and Davidoff AM: Adeno-associated virus vector-mediated delivery of pigment epithelium-derived factor restricts neuroblastoma angiogenesis and growth. J Pediatr Surg 40: 236-243, 2005.

18. Cheung LW, Au SC, Cheung AN, Ngan HY, Tombran-Tink J, Auersperg $\mathrm{N}$ and Wong AS: Pigment epithelium-derived factor is estrogen sensitive and inhibits the growth of human ovarian cancer and ovarian surface epithelial cells. Endocrinology 147: 4179-4191, 2006.

19. Ek ET, Dass CR, Contreras KG and Choong PF: Inhibition of orthotopic osteosarcoma growth and metastasis by multitargeted antitumour activities of pigment epithelium-derived factor. Clin Exp Metastasis 24: 93-106, 2007.

20. Guan M, Jiang H, Xu C, Xu R, Chen Z and Lu Y: Adenovirusmediated PEDF expression inhibits prostate cancer cell growth and results in augmented expression of PAI-2. Cancer Biol Ther 6: 419-425, 2007

21. Zhang L, Chen J, Ke Y, Mansel RE and Jiang WG: Downregulation of PEDF expression by ribozyme transgene in endothelial and lung cancer cells and its impact on angiogenesis in vitro. Oncol Rep 14: 1615-1619, 2005.

22. Sobin LH and Fleming ID: TNM Classification of Malignant Tumours, fifth edition. Union Internationale Contre le Cancer and the American Joint Committee on Cancer. Cancer 80: 1803-1804, 1997.

23. Jiang WG, Davies G, Martin TA, Parr C, Watkins G, Mason MD, Mokbel $\mathrm{K}$ and Mansel RE: Targeting matrilysin and its impact on tumour growth in vivo: the potential implications in breast cancer therapy. Clin Cancer Res 11: 6012-6019, 2005.

24. Jiang WG, Hiscox S, Hallett MB, Horrobin DF, Mansel RE and Puntis MC: Regulation of the expression of E-cadherin on human cancer cells by gamma-linolenic acid (GLA). Cancer Res 55: 5043-5048, 1995.

25. Rosen EM, Meromsky L, Setter E, Vinter DW and Goldberg ID: Smooth muscle-derived factor stimulates mobility of human tumour cells. Invasion Metastasis 10: 49-64, 1990.

26. Jiang WG, Sampson J, Martin TA, Lee-Jones L, Watkins G, Douglas-Jones A, Mokbel K and Mansel RE: Tuberin and hamartin are aberrantly expressed and linked to clinical outcome in human breast cancer: the role of promoter methylation of TSC genes. Eur J Cancer 41: 1628-1636, 2005.

27. Abe R, Shimizu T, Yamagishi S, Shibaki A, Amano S, Inagaki Y, Watanabe H, Sugawara H, Nakamura H, Takeuchi M, Imaizumi T and Shimizu H: Overexpression of pigment epithelium derived factor decreases angiogenesis and inhibits the growth of human malignant melanoma cells in vivo. Am J Pathol 164: 1225-1232, 2004.

28. Guan M, Yam HF, Su B, Chan KP, Pang CP, Liu WW, Zhang WZ and Lu Y: Loss of pigment epithelium derived factor expression in glioma progression. J Clin Pathol 56: 277-282, 2003.

29. Cai J, Parr C, Watkins G, Jiang WG and Boulton M: Decreased pigment epithelium-derived factor expression in human breast cancer progression. Clin Cancer Res 12: 3510-3517, 2006. 